\title{
MORAL HAZARD AND MEDICAL ASSESSMENT
}

\author{
Grant Duncan*
}

Across its history ACC policy on rehabilitation has fluctuated, as has the approach to compensating victims with partial but permanent incapacity. These procedures offer an important window onto shifting ACC attitudes to entitlements, social equity, and cost control, which accompanied the legislative changes of the 1990s. This paper examines the particular methods used by ACC in recent years to assess the capacity of beneficiaries to return to work, as well as methods used to calculate benefits for partial long-term incapacity. The paper argues that these ACC practices reveal the changing strategic relationship between beneficiaries and a costconscious state authority.

\section{INTRODUCTION}

I have been asked to review the changes to ACC during the 1990s with a specific emphasis on long-term disability management. To that effect, I intend to give special attention to the process of work-capacity assessment, but also to the underlying principles of moral hazard that have apparently conditioned the minds of legislators in this matter.

The 1990s in New Zealand will be remembered as the decade of the ascendancy of neo-liberal political rule, and I believe it is important to comprehend the rationality of this approach to government before we proceed too far. Typically, liberal thought takes as its starting-point the autonomous, adult individual, free-willed and self-responsible, in pursuit of the satisfaction of needs and wants. In political theories of liberalism, this autonomous being is positioned in relation to a reified sovereign government, or State, that wields ultimate coercive power. These State powers are thought to be legitimate provided they are deployed for the security of the individual and, at least, do not unduly harm his or her freedom and personal development.

Liberty is thought to place a limitation against the State's powers; it is seen as a "sovereignty of the self", a prior condition and an absolute boundary to the "intrusion" of State coercion.

* Senior Lecturer, Social Policy, Massey University (Albany). 
It is only acknowledged by some political analysts that liberty, thus conceived, is more ideological than real, and that it may be more correctly seen as a construct for the advancement, rather than the limitation, of the art of government. ${ }^{1}$ Those governed under the banner of liberty are more effectively governed, not less so. And, hence, if we observe some of the actual instruments of government, as opposed to the ideals of political rhetoric or theory, we may be more inclined to the view that liberal governance is a subtly pervasive exercise of power, rather than a doctrine about limitations thereto. The instruments of disability management that I will portray in this paper help to illustrate this general point about neo-liberal governance.

To advance this, we need to observe two things: first, the construct of moral hazard - a phenomenon attributed to all insurance systems - and, secondly, the changes brought about by workers' compensation, and consolidated by New Zealand's ACC scheme, which have seen compensation for personal injury determined increasingly by medical - as opposed to legal judgement.

In regard to any kind of insurance, the idea of moral hazard generally assumes that the existence of insurance cover will tend to decrease the insured's motivation to prevent damage, and to increase the likelihood of false or exaggerated compensation claims. In the case of workers' compensation, we have a slightly more complex arrangement, because the premium payer, the employer, is not the same party as those whose injuries are insured, the employees. But, such insurance could be considered to present a moral hazard on both parties: employers may be less motivated to invest in preventing accidents, and workers may be motivated by financial awards to falsify or exaggerate disabilities. The comprehensive, universal nature of ACC, the certainty of cover and the bar on the right to sue, it could be argued, further dilute personal responsibility for safety and increase opportunities for malingering. But this latter point is merely a theoretical inference, and I know of no empirical support for it. Moreover, the comprehensiveness of ACC has tended to prevent a lot of litigation about work-relatedness, as most accident victims are equally well catered for regardless of the circumstances of the injury.

The insurance relationship also creates a kind of moral hazard for the insurers, not just for the insured. ${ }^{2}$ Commercial insurers in particular have incentives to over-sell insurance to some people, to refuse insurance to other people who may well need it, to compete on the basis of unsustainable premiums, and to deny benefits. For example, injury compensation insurance is sometimes sold to self-employed persons, even when it is not needed. It is suggested that a personal trainer, for

1 See Mitchell Dean Governmentality: Power and Rule in Modern Society (Sage, London, 1999); Nicolas Rose and Peter Miller "Political Power beyond the State: Problematics of Government" (1992) 43 British Journal of Sociology 173.

2 Richard Ericson, Dean Barry and Aaron Doyle "The Moral Hazards of Neo-Liberalism: Lessons from the Private Insurance Industry" (2000) 29 Economy and Society 532. 
instance, might cause injury and be sued for exemplary damages, even though the probability of that happening in this country must be infinitesimally small.

Moving on then to the topic of medical assessment, the introduction of no-fault statutory compensation achieves an important change to the process by which compensation is determined and awarded. In the absence of a no-fault scheme, the injured party may need to initiate a legal contest in order to justify and gain compensation. Medical evidence is presented in court, of course, but the existence of a physical injury in itself does not justify compensation. Instead, a finding of negligence is the key to entitlement. A well-administered no-fault scheme, on the other hand, completely changes this process. Medical diagnosis and etiology become the factors determining eligibility for compensation, and this may be further refined by assessments of impairment and of work-capacity to determine financial awards or the length of time on wage-replacement compensation. The process is thus primarily medical and administrative. Appeals to the courts are kept to a minimum, only as a "back-up".

Moral hazard and medical assessment are thus the main focus of this paper. My intention is to observe how these principles and practices were applied to accident compensation law in New Zealand during the "neo-liberal Nineties".

\section{WORK CAPACITY AND THE 1992 ACT}

In 1992, during the passage of the Accident, Rehabilitation and Compensation Insurance Act 1972, I served on an in-house panel examining the operational implications of that legislation. At the time, as I recall, the main areas of public criticism of the Act were the removal of lump sums and the tighter definitions of "accident" and "medical misadventure". The provisions for an assessment of work-capacity seemed to be equally significant, but they largely went unnoticed. Oddly enough, this provision was not fully implemented until 1997 (after a failed trial run and an amendment to the law); but the provisions for work-capacity testing have survived through the Accident Insurance Act 1998 privatising workers' compensation and to the present after renationalisation. There appears therefore to be considerable political consensus about the need for an assessment of work-capacity to test continuing eligibility for weekly compensation for lost income, the single most costly type of compensation provided by ACC.

To understand its underlying purpose, we have to note two things. First, there was the steady growth in ACC's compensation expenditure during the 1980s, due significantly to prolonged claims for weekly compensation. Secondly, there was the claim made by the then Minister, Hon Bill Birch, that ACC was harbouring "hidden unemployment". By this he could only have meant that there were claimants receiving long-term weekly compensation who had effectively recovered from their injuries, and yet who had not returned to paid employment for unspecified reasons. In a stroke, he redefined the status of many claimants from "injured person" to "unemployed person" and served notice that their eligibility under ACC was about to end. 
What followed was the development and field-trial of a work-capacity assessment based on fairly complex scales of impairment, disability and handicap. Claimants who rated over 85 per cent "fit for work" could have their weekly compensation terminated with three months' notice. For reasons that were never fully explained, this approach was scrapped, and the law empowering workcapacity assessment was rewritten in the 1996 Amendment.

The new system, which is still in force, came into effect in 1997, but is less rigorous than the initial scales that had been trialed and validated five years earlier. The present work-capacity assessment simply involves an occupational assessment of the claimant's transferable skills and potential for employment, followed by a medical assessment to determine for which of those occupations the claimant would be medically fit due to the injuries covered by the Act. The technical validity of this approach is very limited, but the law adopts it nonetheless. I have critically analysed this assessment process elsewhere, ${ }^{3}$ but my present concern is the fact that claimants are not permitted, after seeking medical advice, to determine for themselves when they are fit for work. And rightly so, one may reply. After all, who can trust people when they are receiving compensation payments at eighty per cent of previous earnings?

This is where the concept of moral hazard steps into the equation. If we assume that all individuals conduct their lives on the basis of rational calculation aimed at maximising the utility of the resources at one's personal disposal, then the logical conclusion is to assume that injury victims are always inclined to malinger, and that they will cheat on insurers, public or private, whenever possible. If they say they are still unfit for work, do not believe them; send them off instead to an "objective" physician to verify their status. The problem with this assumption of distrust, which is now built in to law, is that it does not recognise that there may also be strong willingness to return to work, to retrain for work if need be, but on one's own terms, rather than under the direction of administrators. And hence there is a source of frequent conflict.

A similar issue arises in regard to the assessment of permanent impairment. The Accident Rehabilitation and Compensation Insurance Act 1992 removed lump sums for permanent impairment and replaced them with a rather unpopular periodic payment called the independence allowance. The initial assessment for this allowance was published in regulations and was based on scales of self-reported functional limitations in activities of daily living. This assessment procedure was disliked by many claimants because of its intrusive and often inappropriate questions. Predictably, the Government resorted to the supposedly more "objective" American Medical Association's Guides to the Evaluation of Permanent Impairment (AMA Guides). The perennial problem with this approach is that impairment scales do not evaluate the actual impact of a permanent injury on a person's real-life functional abilities. In short, impairment can be determined

3 See Grant Duncan "The Assessment of Residual Capacity for Work: Easier Said than Done" (1999) 12 Social Policy Journal of New Zealand 35; Grant Duncan "Social Policy, Work Capacity and Governmentality" (2000) 38 Sites 31 . 
by medical observation, but disability is a much broader issue altogether. A physician in a consulting room is, strictly speaking, ill-equipped to evaluate disability or work-fitness, and yet governments keep resorting to impairment scales for their greater reliability and supposed objectivity. The AMA Guides have now been enshrined, quite inappropriately according to the Guides themselves, as the underlying determinant of lump sums under the Injury Prevention, Rehabilitation, and Compensation Act 2001. This is in spite of the many authorities in this field who have argued that they should not be used to determine disability, and that they are a tool for limiting financial liabilities and for cost-shifting rather than for identifying genuine needs. ${ }^{4}$

Now, there is an issue underlying all of this that we in New Zealand have failed to debate in full - the question of permanent partial disability. A lot has been said about the justification for having lump sums for permanent partial disability, especially during the reforms of the 1990s; but we have tended to adopt systems that only partially address this issue.

Let us consider a hypothetical case. A worker - we will call him Bill - has many years of experience in the construction industry, mostly with scaffolding subcontractors. One day he badly injures his left knee (not necessarily on the job), and this results in considerable time off work due to the ongoing stiffness and pain in the affected limb. This injury results in a permanent impairment, and, despite efforts to return to work, medical advice indicates that continuing in his previous occupation is not possible. Eventually, the permanent impairment is rated using the AMA Guides. Prior to the reintroduction of lump sums under the Injury Prevention, Rehabilitation, and Compensation Act 2001, this would have entitled him to a small periodic payment in addition to weekly compensation for loss of earnings.

Now, while Bill's safe range of mobility is somewhat restricted, to the extent that he cannot return to his previous occupation, he is capable of some form of paid work. So, in due course, ACC requires him to undertake a work-capacity test. The occupational assessor notes that he has good interpersonal skills and a driving license, and so suggests that he could undertake employment as either a call-centre operator or a taxi driver. He is then referred on to a medical assessor who is satisfied that either occupation could be undertaken by Bill, given the nature of the physical impairment to his knee, but notes that, as a taxi driver, it would be best if the cab had an automatic transmission. ACC then informs Bill that he is fit for work, and terminates his weekly compensation with three months notice.

Let us further suppose that Bill has investigated the possibilities for employment in the occupations that have been recommended to him, and he discovers that, given those options, he is

4 Martha McCluskey "The Illusion of Efficiency in Workers' Compensation Reform" (1998) 50 Rutgers L Rev 657; Ellen Smith Pryor "Flawed Promises: A Critical Evaluation of the American Medical Association's Guides to the Evaluation of Permanent Impairment" (1990) 103 Harv L Rev 964; E Michael Shanahan and Leon le Leu "The American Medical Association's Guides to the Evaluation of Permanent Impairment" (1993) 10 Journal of Occupational Health and Safety - Australia and New Zealand 323. 
very unlikely to earn the good income that he previously enjoyed in the scaffolding business. He finds the idea of answering phones or driving a cab all day demeaning, given the fact that he had previously taken pride in himself as a skilled and valued worker in a dynamic industry. He hoped instead to retrain in a skilled - but sedentary - trade, allied to the construction industry, such as drafting. ACC, however, is under no obligation to support him in the lengthy course of tertiary study required to achieve the relevant qualifications, especially while he is technically fit for another job. Legislation requires ACC to consider the cost-effectiveness of any vocational rehabilitation programme, and, failing a return to the previous occupation, is only required to aim to achieve a capacity for work - in any occupation, regardless of the availability of an actual job. Bill could think about undertaking retraining in drafting at his own cost; but this is a proposition that has been pressed upon him as a result of an accident, not of his own choosing.

It is also pertinent to reflect on the widely-held view among policy-makers and the community at large that governments need to be setting objectives that support the raising of job-relevant skills through education and training policies. Someone in Bill's position could be forgiven for thinking that government has overlooked this goal when it comes to persons permanently incapacitated for their normal occupations due to injury.

Retraining, however, is not the only way of recognising permanent partial disability. Until the Accident Rehabilitation and Compensation Insurance Act 1992, ACC did have provision for permanent pensions to compensate for loss of earning capacity. Such a provision might have meant that Bill would have had permanent compensation to make up for the difference between what he earns in his new occupation as a call-centre operator, and what he would have been earning in the scaffolding trade. There are some very obvious problems with this approach. We no longer have a labour market with fixed national award rates and security of employment. So, it is simply unrealistic to make guesses about how much a person would have earned if only they had not been injured. Furthermore, the permanent pensions were vulnerable to misuse by claimants who often found it possible to improve their incomes from employment, and yet retained the entitlement. To give the message that the person's earning capacity is compromised forever risks being proven wrong. For this kind of reason, I am glad to see that they have not been reintroduced by the Labourled Government in the Injury Prevention, Rehabilitation, and Compensation Act 2001.

The fact is, that the cost consequent upon Bill's incapacity due to accident have now been shifted further onto his shoulders. He now faces a reduced period of wage-replacement support for his economic losses and may now have to pay for the consequences of a possible life-long reduction in his occupational status and his earning capacity.

Another peculiar possibility emerges from his situation. ACC ceases his compensation on the assumption that he can answer phones or drive a cab, and ceases all responsibility for the outcomes of this decision. But Bill is now unsupervised and is free to disguise his injury and to return to scaffolding, against medical advice, and thus risk re-injury. I have to admit that I have not heard of a case of this, and I know that ACC officials think it irrelevant of me to raise this question. But it 
does trouble me that judgments of work-capacity are being made and there is no follow-up supervision to check either the validity of that decision or the outcome for the persons concerned.

\section{THE MORAL HAZARD EFFECT}

Getting back to the economic problem of moral hazard: the reforms of ACC in the 1990s, as they concern permanent partial disability and work-capacity, have now achieved a bi-partisan consensus in New Zealand, illustrated by the fact that the Injury Prevention, Rehabilitation, and Compensation Act 2001 seems to retain the changes made since 1992. These new provisions are justified by moral-economic claims about the effects of reducing benefit entitlements. More generous benefits are said to increase the frequency and duration of claims. ${ }^{5}$ Following through with this economic logic, therefore, a reduction in the generosity or duration of compensation claims will reduce employers' premiums. In the absence of workers' compensation, more hazardous jobs would have to be offset by higher wages (a wage premium) as a "price" for the higher risk, at least until they reach a cost at which it would become cheaper for the employer to eliminate or minimize the hazard. (This assumes also that the prospective employee has full prior knowledge of the health and safety risks, and of the going wage-rate in the market.) Economists would argue that the introduction of compensation insurance premiums into the market substitutes for wage premiums as a price signal, and hence may influence the level of investment in health and safety in the workplace. ${ }^{6}$ Injury insurance premiums do not account for the full costs of accidents to employers, however, as many, often hidden, costs - such as property damage and replacement of employees - are not covered by workers' compensation. Lower compensation costs, under this economic logic, would therefore reduce the incentive for employers to invest in accident prevention, hence raising the frequency of accidents. Similarly, the pursuit of competitively low premiums simply encourages employers and insurers to suppress the lodging and acceptance of compensation claims and to force employees to return to work inappropriately early, thus risking complications in recovery and re-injury. I have already noted the risk that work-capacity testing may result in a return to a previous occupation, regardless of medical advice. Such incentives must be taken into account as concerns that undermine the insurance industry's usual claims that the pursuit of lower premiums motivates employers to adopt improved safety standards and rehabilitation.

In effect, the methods of limiting liabilities experimented with in the 1990s (experience rating as well as medical assessment) do not necessarily reduce costs or mitigate the effects of moral hazard, given the apparent incentives in the market. In fact, they simply transfer the costs and

5 Richard J Butler "Economic Determinants of Workers' Compensation Trends" (1994) 61 Journal of Risk and Insurance 383; Leon S Robertson and J Phillip Keeve "Worker Injuries: The Effects of Workers' Compensation and OSHA Inspections" (1983) 8 Journal of Health Politics, Policy and Law 581.

6 See John D Loeser, Stephen E Henderlite and Douglas A Conrad "Incentive Effects of Workers' Compensation Benefits: A Literature Synthesis" (1995) 52 Medical Care Research and Review 34. 
consequences of injuries away from employers and insurers and onto the injured worker. In controlling the moral-hazard effects of workers' behaviour, they simply encourage moral hazard among employers and insurers. As Martha McCluskey puts it: ${ }^{7}$

The debate over appropriate workers' compensation benefits levels is not simply a matter of increasing

or decreasing 'moral hazard' and its resulting costs, but is a normative choice of whose moral hazard

should be controlled, workers' or employers' (and insurers') .

At this point I would recommend reading Eric Schlosser's analysis of safety and health and workers' compensation in the United States meat industry for a horrifying account of how employers and insurers, in an environment with inadequate compensation benefits and weak OSH enforcement, are in effect given a licence to harm and maim, purely in the interests of profit margins. ${ }^{8}$

\section{FREEDOM TO CHOOSE?}

I would like to make one last point about the predicament in which Bill finds himself. While his rights and his conduct as a claimant are governed under the liberal principles referred to above, there is one form of autonomous decision-making that he loses when he is tested for work-capacity: that is the right to decide for himself when he is ready to return to work, at least as long as he continues to benefit from the right to compensation. One may say that this compromise of his liberty is perfectly reasonable, due to moral hazard. After all, it is not uncommon for compensation benefits to be abused. As an economic subject, homo economicus, he is thought to be rationally calculating the costs and benefits of wages, safety behaviours and compensation entitlements. In the interests of industrial efficiency, his propensity to moral hazard has to be brought under control; and to achieve this his ability to choose freely his status in relation to paid work must be taken from him. His rights become obligations rather than liberties, and his ability to define his future occupation falls into the hands of State-appointed professionals. Apparently his liberty was more conditional than was first thought; but the fact that he is seen to be "free" paradoxically makes it easier to justify the governing of his personal conduct.

Unfortunately, methods for determining work capacity are notoriously unreliable, and their validity is especially questionable when conducted in a consulting room, without direct reference to the tasks required of an actual job for which the claimant may be eligible. Ironically, the workcapacity test that was envisaged by the 1992 Act, and later scrapped, was found in field-trials to be more reliable than physicians' opinions, and yet the assessment method that ACC now employs

7 Martha McCluskey "The Illusion of Efficiency in Workers' Compensation Reform" (1998) 59 Rutgers L Rev 657, 818.

8 Eric Schlosser Fast Food Nation (Penguin, London, 2002). 
rests finally on the opinion of one physician. The vigorous reliance on work-capacity testing is perhaps a symptom of the insurer's moral hazard.

But let us not forget that Bill is a citizen who forgoes the right to sue for compensation for the injury to his knee, the consequences of which have included an end to the occupation that he had enjoyed and that would otherwise have supported his well-being for some time to come. Compensation schemes appear to have progressively undermined the "social contract" on which this compromise was based. This has occurred through the continual reduction of the types and the levels of compensation available, beneath those that may otherwise have been recoverable. Bill cannot sue for pain and suffering and loss of enjoyment of life, nor can he sue for the costs of retraining in an equally skilled trade. But, neither will ACC provide no-fault compensatory benefits for those specific damages. But the idea of a social contract implies the rational consent of the governed. And herein lies my introductory point about the illusory nature of liberal thought. Regardless of the philosophical debate about the nature of personal free will, the assumption of a rational autonomous individual, whose freedom must be protected from the exertions of government, is a political fiction justifying the exercise of government. Once ACC defines Bill as fit for work, regardless of what he thinks or actually does, he is "free" to find a job. He is said to consent to the institutional arrangements that govern his conduct because any rational person would supposedly prefer those arrangements over having a day in court. And he is seen to be better off finding his own employment rather than being "dependent" on ACC - an institution that is itself the product of modern industrial employment, and was invented in order to legitimise and underwrite the risks inherent in modern-day activities.

\section{CONCLUSION}

The insurance-based principles of the Accident Rehabilitation and Compensation Insurance Act 1992 brought in the concepts of individual (as opposed to community) responsibility and of workcapacity assessment. This was soon followed by impairment-based rating to determine noneconomic loss. These principles fed through to the Accident Insurance Act 1998's introduction of competitive provision of workers' compensation, and they have survived unquestioned through the Labour-led reforms of 2001.

It is time New Zealand had a more robust debate about permanent partial disability and the rights and obligations contingent upon it. Such a debate needs to make the current neo-liberal assumptions of present law more explicit, and it needs to consider principles alternative to those of moral hazard, individual responsibility and medical objectivity. We need to take a broader look at the issues of rights and needs for those whose livelihoods and occupational skills are threatened by permanent partial disability. 
